\title{
Evaluation of forming forces in ultrasonic incremental sheet metal forming
}

\author{
Pengyang $\mathrm{Li}^{\mathrm{a}}{ }^{\mathrm{a},{ }_{*}}$, Jin $\mathrm{He}^{\mathrm{a}}$, Qiang Liu ${ }^{\mathrm{a}}$, Mingshuan Yang ${ }^{\mathrm{a}}$, QuandaiWang ${ }^{\mathrm{a}, *}$,Qilong Yuan ${ }^{\mathrm{a}}$, Yan $\mathrm{Li}^{\mathrm{a}}$ \\ ${ }^{a}$ Xi'an University of Technology, Xi'an 710048, China
}

${ }^{\mathrm{b}}$ The State Key Laboratory of Mechanical Transmissions, Chongqing University, Chongqing 400044, China

E-mail addresses:lipengyang@xaut.edu.cn(P.Li), wangquandai@xaut.edu.cn(Q.Wang).

\begin{abstract}
In this paper, a new type of sheet metal forming technology using ultrasonic vibration applied to SPIF (single point incremental forming) process is presented. Forming force during forming process can induce fracture and affect accuracy of the sheet metal. Design of ultrasonic sheet metal forming equipment can be based on this study, which takes into account magnitude and changing law of the forming force. ABAQUS finite element software was used to simulate and analyze influence of different frequencies and amplitudes of ultrasonic vibration on the forming force in single point incremental forming process. Results show that ultrasonic vibration can reduce forming force and improve surface quality of the forming process. In addition, an experimental system using ultrasonic single point incremental forming was designed. Effect of the amplitude on ultrasonic vibration was studied experimentally. Experimental results were consistent with the result from finite element simulation.
\end{abstract}

Keywords: ultrasonic vibration; single point incremental forming; forming force;

\section{Introduction}

Currently, Small batch production or prototyping of sheet metal is formed primarily employing conventional forming processes with conventional tool and die sets. For example, in the aerospace industry, about 200 stamping dies are used each year for a typical batch size of about 5000 components [1]. However, financial and energy costs are very expensive to manufacture special tools and die sets. In addition, these tools and die sets need to be stored in free time, resulting in inventories that occupy large amounts of space and are very expensive to maintain. Therefore, using traditional forming processes of sheet metal to manufacture small batch production is not very desirable.

In early 1990s, Matsubara first proposed the use of SPIF (single point incremental forming) in manufacturing, and this process is based on the "layered manufacturing" concept used in rapid prototype manufacturing technology [2]. In this process, a complex 3D shape is discretized into a series of two-dimensional contour layers, and processing is implemented the tool on the two-dimensional surface based on a predefined contour layer by layer. Thus, such a process allows digital manufacturing of sheet metal. An advantage associated with using SPIF is the quick turnaround time for development of prototypes. Thus, development and production of multi-variety products in small batches can be achieved at low cost. Application of SPIF technology prevents disadvantages (e.g. lots of die sets, high costs) in products, often associated with traditional sheet metal forming. However, SPIF method has drawbacks such as high forming force, poor quality, and difficulty in forming shape complex parts.

Durante and et al.[3] proposed based on results using finite element simulation and experiments that rotation speed of the tool would affect the friction coefficient, which in turn would result in a change in the required forming force, forming temperature and forming precision. Henrard and et al. [4] used finite element 
simulation and experiments to verify magnitude of forming force at different forming angles. In addition, influence of the constitutive relation and hardening law on forming force at different forming angles was analyzed. Aerens et al. [5] deduced an empirical formula to predict forming load. This formula was used to calculate axial force in steady state and the validity of this formula was verified by experiments. This formula can be used to predict forming force in the SPIF process. Bagudanch et al. [6] analyzed influence of tool diameter and spindle speed on forming force. They found that high-speed operation of the spindle resulted in an increase in forming temperature due to friction. Belchior and et al. [7] used finite element method simulating the SPIF process, and then predicted the forming force accurately.

Ultrasonic vibration plastic processing originated in 1950's. Austria's Blaha et al. [8] added ultrasonic vibration to single crystal zinc static stretching experiments. In this experiment, yield stress and flow stress of the material were found to decrease. This phenomenon is referred to as the Blaha effect. Later, this phenomenon was summarized as a volume effect of ultrasonic vibration plastic processing (i.e. effect of vibration on internal stress in metal plastic flowing on). Another effect of ultrasonic vibration molding process was a surface effect, which influenced friction between work piece and the mold. Compared to traditional plastic forming, ultrasonic vibration forming significantly reduces flow stress of the material, improves material forming limit and product quality [9]. Green [10] performed various experiments to study the effect of the ultrasonic energy during deformation of different materials. He found that the ultrasonic energy intensity is proportional to the reduction of the yielding strength. Huang et al. [11] conducted experimental studies on ultrasonic assisted upsetting processes and found that ultrasonic vibration can reduce the average forming force during the upsetting due to the decrease in friction force. Huang and et al. [12] performed experiments on three stainless steel 304 foils of different thicknesses to determine the influence of ultrasonic vibrations on micro-cup formability and the limit drawing ratio (LDR). They found out that the ultrasonic vibration will not only increase the LDR, but also it will decrease the punch force. Rasoli et al. [13] performed experimental studies on the effect of ultrasonic longitudinal vibration on the pipe spinning process. The results showed that the ultrasonic vibration with high power could reduce radial force of 4 to 13 percent. Inoue [14] performed experiments to study ultrasonic assisted metal tube drawing and found that, for thick steel tubes, no notable reduction in drawing force was observed. However, damages of the opening decreased and surface roughness and lifespan of the die were improved. Vahdati et al. [15] designed and manufactured an ultrasonic vibrating forming tool for ISF. And they performed experiments to study the effect of the ultrasonic vibration on ISF and found that, the ultrasonic vibration causes reduction of the applied force average on the forming tool axis, decrease of the spring-back rate and reduction of the formed sample surface roughness.

Based on the advantages of ultrasonic vibration in plastic forming, the ultrasonic vibration was introduced into SPIF. US-SPIF (Ultrasonic single point incremental forming) applies a regular vibration load to the tool using an ultrasonic source during SPIF. This enabled the tool to periodically press the sheet metal in the axial direction. Fig. 1 illustrates the US-SPIF principle.

SPIF mainly depends on localized squeeze between the tool and sheet metal. Thus, forming force has an impact on fracture and precision of the sheet metal. There are direct relationship between the forming forces and the stress level of the workpiece. Stress can be related to the evolution of the plastic strain, which determines the structural integrity of the formed component [6]. Also, design of the ultrasonic sheet forming equipment (e.g. stiffness, power, size) is related to the magnitude and changing law of the forming force. A good knowledge of the forming forces can contribute to the preservation of the tools and the machinery used in the process. Due to these reasons, investigation of the impact of forming force on SPIF has good application value $[16,17]$.

In this paper, ABAQUS was used as the finite element software to simulate and analyze changing law of the forming force as a function of frequency and amplitude of ultrasonic variation. Here, in addition to the simulations, an experimental US-SPIF system was designed to investigate the effect of the ultrasonic vibration 
amplitude.

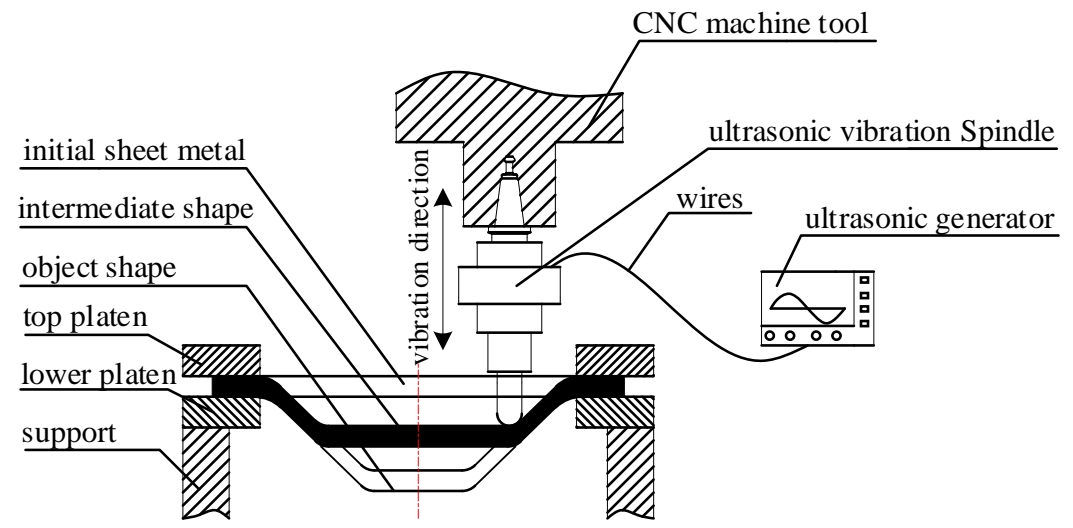

Fig. 1 US-SPIF principle diagram

\section{Design of ultrasonic vibration system}

An ultrasonic vibration system with the first order longitudinal resonant frequency of $20 \mathrm{kHz}$ was designed in this text. And the ultrasonic vibration system was comprised of an ultrasonic generator and ultrasonic vibration spindle device. Fig.2 is a schematic diagram of the ultrasonic vibration spindle device comprising of a transducer, amplitude transformer, spindle shell, collector ring, tool shank and forming tool. During the forming process, a high frequency electrical signal which was the output of ultrasonic generator was converted to ultrasonic vibration by the transducer. Next, this vibration was transmitted to the tool through amplification using a transformer.

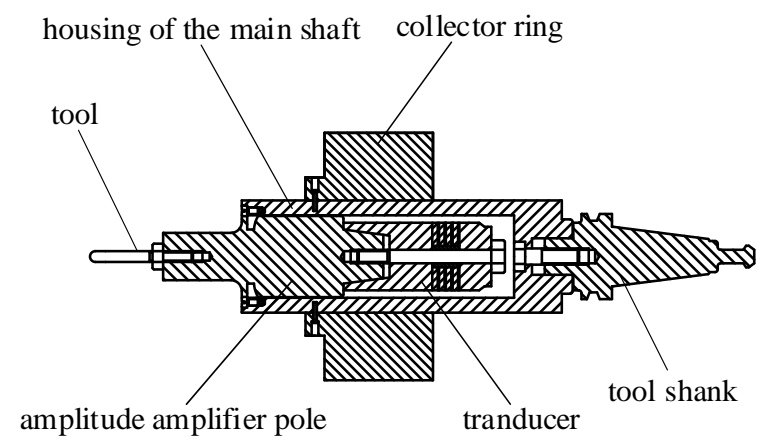

Fig.2 Ultrasonic vibration spindle device structure diagram

Spindle shell and tool shank were connected by bolts, the amplitude transformer was fixed to the spindle shell through a flange. In this way, transfer of ultrasonic vibration to the tool with minimum losses can be ensured. This device can be installed onto the spindle of a vertical milling machine directly through the tool shank and then used for forming sheet metal.

The tool and amplitude transformer were connected by screw threads to ensure stability of vibration transmission. However, a tool connected by a screw thread was found to break in a short time duration in the experiments. Analysis of the system revealed that due to stress concentration at the bottom of the threaded connection caused the tool to break. In order to eliminate stress concentration, a nut was installed on the bottom part of the tool. This design allows transfer of a portion of vibration to the tool through the screw threads and the remaining portion through the nut. As result, stress concentration was prevented. The redesigned tool had better rigidity after quenching. Fig. 3 shows the unimproved, cracked and improved tools. 


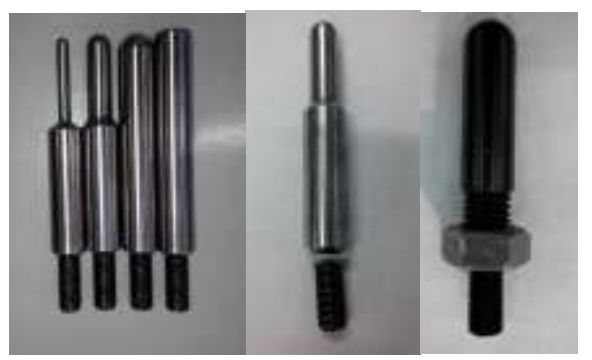

unimproved tool cracked tool improved tool

Fig.3 Tools

During US-SPIF, the tool was required to vibrate with high frequency in the axial direction and rotates. In order to prevent wire winding together, it was necessary to design a collector. Fig.4 shows the ultrasonic vibration spindle device used in the experiments. Experiments have been conducted to measure its longitudinal amplitude. The results show that when the power of the ultrasonic generator are 115w, 246w, 488w, 606w, 967w, $1203 \mathrm{w}$, the corresponding amplitudes are $5 \mu \mathrm{m}, 10 \mu \mathrm{m}, 20 \mu \mathrm{m}, 30 \mu \mathrm{m}, 40 \mu \mathrm{m}, 50 \mu \mathrm{m}$. Fig. 5 shows the ultrasonic vibration system in this paper.

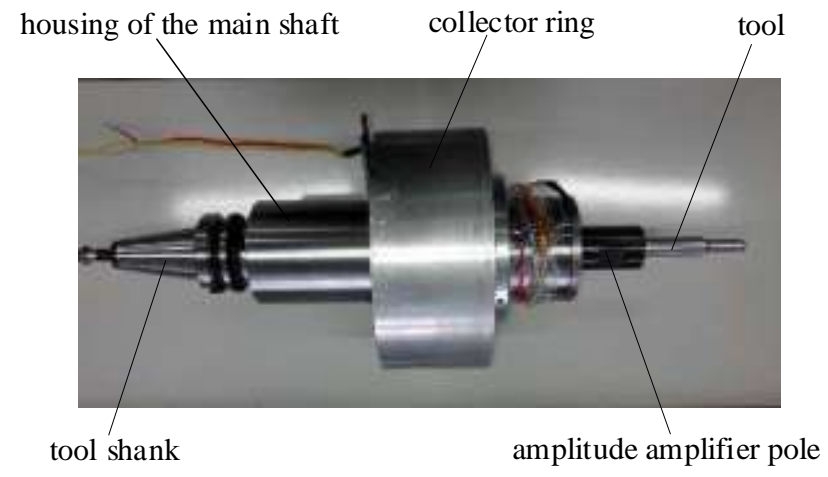

Fig.4 Ultrasonic vibration spindle device

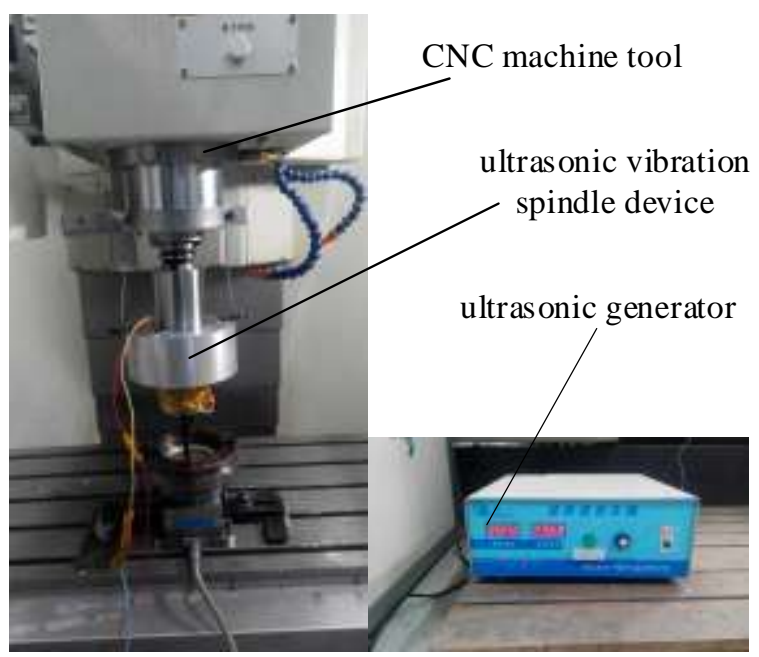

Fig.5 Ultrasonic vibration system

\section{Theoretical analysis of forming force in US-SPIF}

Forming force in US-SPIF process can be divided into a tangential forming force $F_{t}$, radial forming force $F_{r}$ and axial forming force $F_{z}$. Magnitude of the forces $F_{x}, F_{y}$, and $F_{z}$, can be directly obtained using finite element simulation and experiments. Direction and relationship are shown in Fig.6 and eq.'s (1) - (3). 


$$
\begin{gathered}
F_{x y}=\sqrt{F_{x}^{2}+F_{y}^{2}} \\
F_{r}=-\operatorname{sign}\left(F_{x}\right) F_{x y} \times \cos (\pi-\theta-\psi)=-\operatorname{sign}\left(F_{x}\right) \sqrt{F_{x}^{2}+F_{y}^{2}} \times \cos (\theta+\psi) \\
F_{t}=\operatorname{sign}\left(F_{x}\right) F_{x y} \times \sin (\pi-\theta-\psi)=\operatorname{sign}\left(F_{x}\right) \sqrt{F_{x}^{2}+F_{y}^{2}} \times \sin (\theta+\psi)
\end{gathered}
$$

Where, $\theta$ is the moving path angle of the tool, $\psi$ is the angle between $F_{x}$ and $F_{y}$.
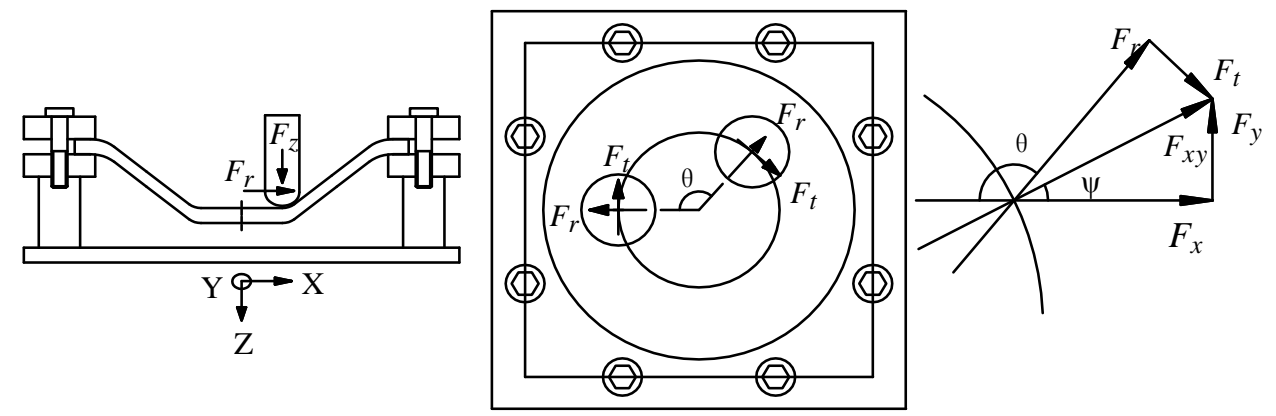

Fig.6 Direction of $F_{x}, F_{y}, F_{x y}, F_{z}, F_{r}$ and $F_{t}$

Duflou et al. [18] and Filice et al [19] have carried out experiments to research forming force in the process of SPIF. And the results show that the forming force trends In the SPIF process were classified as follows: Steady state, Polynomial, Monotonically decreasing; When one contour of the tool path was completed, the axial component of the axial force $F_{z}$ drop to zero, then reaches a peak at the step down and finally reached a stable value, while $F_{x}$ and $F_{y}$ followed a sinusoidal trend. The magnitude of $F_{x}$ and $F_{y}$ was relatively small compared to $F_{z}$, and their impact on sheet forming was relatively small. So in the SPIF process, the axial component $F_{z}$ was the predominant one.

In SPIF process, the tool and the sheet metal was always contact with each other, so the change range of the magnitude of axial force is relatively small in a same contour of the tool path. However, in US-SPIF process, the tool vibrated in axial direction with high frequency, therefore, axial force is a pulse force. Fig.7 shows a vibrational waveform of the tool in US-SPIF process. Only in $T_{c}$ period of a vibration cycle, the tool and sheet metal contact with each other, which will result in a large instantaneous axial force. The mean axial force of the US-SPIF in one cycle is defined as:

$$
F_{\text {mean }}=\frac{1}{n} \sum_{i=1}^{n} F_{i}
$$

Where, $F_{\text {mean }}$ is the mean axial force; $i$ is the number of sampling point of time; $n$ is the total number of sampling points; $F_{i}$ is the axial force of $i$ point;

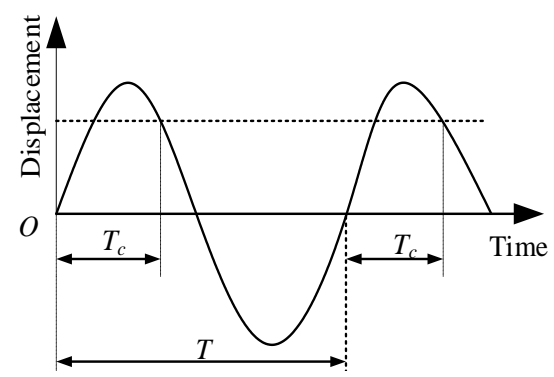

Fig.7 Vibrational waveform of the tool

\section{Finite element simulation of forming force}




\subsection{Establishment of finite element model}

In this paper, ABAQUS was used for finite element numerical simulation of the US-SPIF process. The model consists of an upper and lower pressure plate, tool and sheet metal. Diameter of the tool was $12 \mathrm{~mm}$. A square sheet metal with side length of $140 \mathrm{~mm}$ and $1 \mathrm{~mm}$ thick before forming was used. The upper and lower pressure plates were in the form of a circular ring with an outer ring radius of $70 \mathrm{~mm}$ and inner ring radius of $55 \mathrm{~mm}$. In the forming process, tool and upper and lower pressure plates were almost no deformed, and this had little effect on simulation results. Therefore, upper and lower pressure plates and tool were considered as rigid bodies for analysis. In this paper, shell element is selected for the sheet metal to save calculation time and increase efficiency.

Q235 is selected as the material of sheet metal with Young modulus of 203GPa, tensile strength of 391Mpa, and Poisson's ratios of 0.31. Experimental tests have been conducted to acquire its tensile stress-strain curve, as shown in Fig.8.

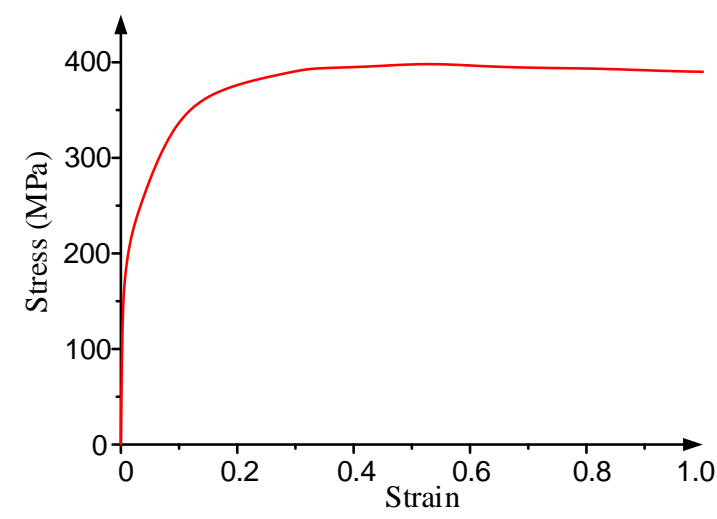

Fig.8 stress-strain curve of Q235

Fig.9 shows the trajectory of the tool in SPIF process. A conical part with the wall angle of $45^{\circ} \mathrm{can}$ be formed when the tool moved according to this trajectory.

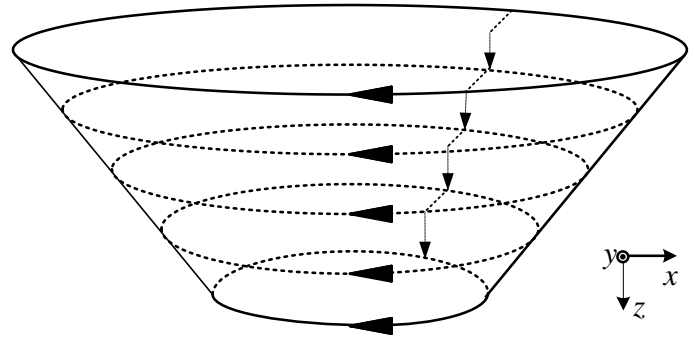

Fig.9 trajectory of the tool

The trajectory of the forming tool can be controlled by setting a cycle amplitude curve. Here, tool was controlled to form a circular trajectory in the numerical simulation. The trajectory in $X, Y$ direction is given as:

$$
\begin{aligned}
& X=U \cos 2 \pi t \\
& Y=U \sin 2 \pi t
\end{aligned}
$$

Where, $U$ is radius of the circular trajectory and $t$ is the forming time.

Circular trajectory of the tool was formed by combining movement in $X$ and $Y$ directions.

During the US-SPIF, the tool moves at high frequency with short displacements (ultrasonic vibration) in the thickness direction. Ultrasonic vibration of the tool in the thickness direction was set by the periodic amplitude curve. Path of the tool in $z$ direction is given by:

$$
Z=A \sin (2 \pi f t)
$$

Where, $A$ is amplitude of the ultrasonic vibration and $f$ is vibration frequency. 
Fig.10 shows the final shape of the sheet metal simulated by ABAQUS software.

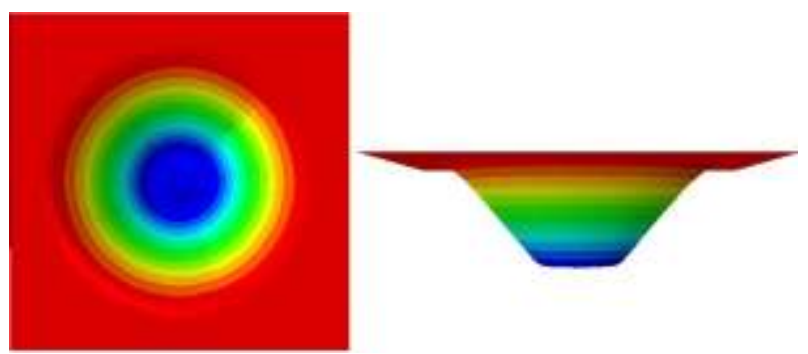

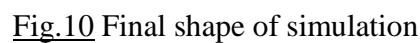

\subsection{Study of forming force}

A critical advantage of adding ultrasonic vibration to the spindle is the reduced forming force in SPIF. Simulating the magnitude of forming force provides the basis for selecting frequency and amplitude of the ultrasonic vibration. In addition, it also provides a reference for design of the US-SPIF machine.

\subsubsection{Assessment of US-SPIF force evolution}

Fig.11 shows changes in the forming force curve during the forming process acquired by simulation of ABAQUS software. As shown, axial force gradually increased with time and stabilizes after 10 seconds. At the start of the forming process, rebound and tension of the sheet metal were small. As a result, axial force was relatively smaller than balance point (about 10 seconds)). After 10s, rebound and tension were balanced resulting in a balanced axial force with maximum magnitude.
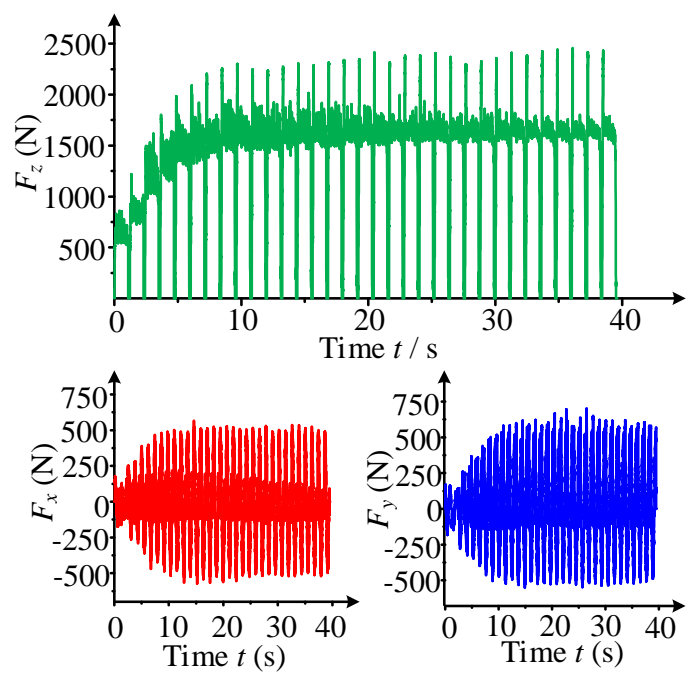

Fig.11 Change in forming force $\mathrm{F}$ during the forming process

Fig. 12 shows change in the forming force between 2 cycles. It can be seen from the figure that in each cycle of forming process there was an initial large increase in the axial force, which stabilized in $0.05 \mathrm{~s}$, and finally there was sharp decrease in the magnitude of the force. Due to rebound of the sheet, fluctuations in axial force were observed during each cycle of the forming process. 


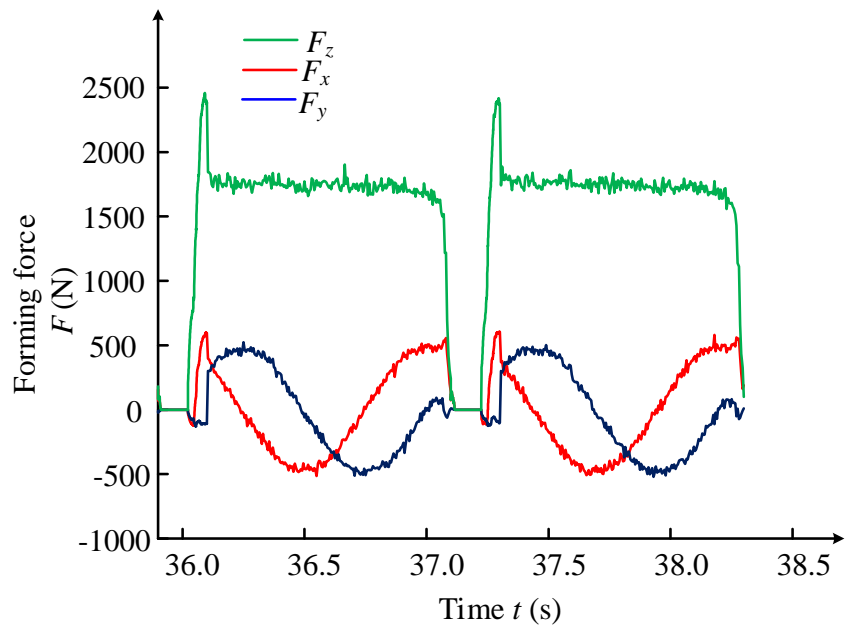

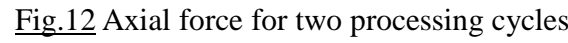

It can be seen from Fig.11 and Fig.12 that magnitude of $F_{x}$ and $F_{y}$ was also found to cyclically fluctuate up and down with time. Fluctuation range increased gradually with forming time and finally stabilized. In each cycle of forming process, tool orbits around the center of plate material. Thus, in this forming process, direction of $F_{t}$ and $F_{r}$ was constantly changing.

It can be seen from Fig. 10 and Fig.11 that magnitude of $F_{x}$ and $F_{y}$ was relatively small, and their impact on sheet forming was relatively small. Due to this, primary focus here is the effect of ultrasonic vibration on axial force $F_{z}$.

The trend of forming force for simulation are basically consistent with the experimental results in Ref. [18], which can verify the correctness of the simulation to a certain extent.

\subsubsection{Forming force at different frequencies}

Axial forces were simulated at different vibration frequencies using finite element simulation. Fig.13 shows the relationship for axial force at different frequencies along with depth in $z$ direction. Each point in the figure is the average value of axial force in the layer of the forming plate at a certain frequency. As seen from the figure, increase in the depth of $z$ direction, first causes a gradual increase in axial force. This increase is followed with the axial force stabilizing and reaching a steady state value. Variation of axial force with ultrasonic vibration was found to be consistent with trend without ultrasonic vibration. During the forming process for sheet metal, both rebound and deformation of sheet were relatively small at first. As a result, axial force was small. As the forming process progressed, both rebound and deformation of the sheet gradually stabilized and reached a maximum value. At this time, axial force is at its maximum value and reached a stable steady state value.

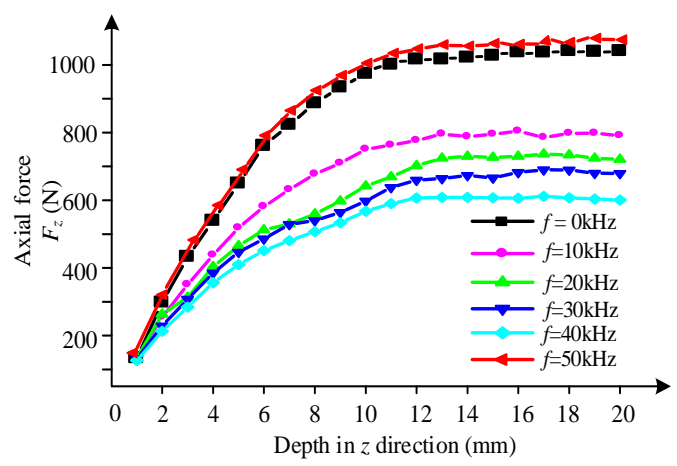

Fig.13 The mean axial force applied amplitude along with depth in z direction

Fig.14 shows the relationship between ultrasonic vibration frequency and mean axial force during the forming process. Here, magnitude of axial force at each frequency is represented by steady state value. It can be 
seen from the figure at $f=0 \mathrm{kHz}$ to $40 \mathrm{kHz}$, axial force gradually decreased with increase in vibration frequency. However, for $f>40 \mathrm{kHz}$, axial force increases rapidly with increase in frequency, and was larger than the axial force without vibration at $f=50 \mathrm{kHz}$. When frequency was less than $40 \mathrm{kHz}$, increase in frequency resulted in reduced contact time contact between the tool and sheet. For frequency larger than $40 \mathrm{kHz}$, the contact time contact between the tool and sheet material were increased with the frequency increase due to increased rebound. Also, average axial force for this case increased significantly, and was greater than axial force without vibration at $f=50 \mathrm{kHz}$.

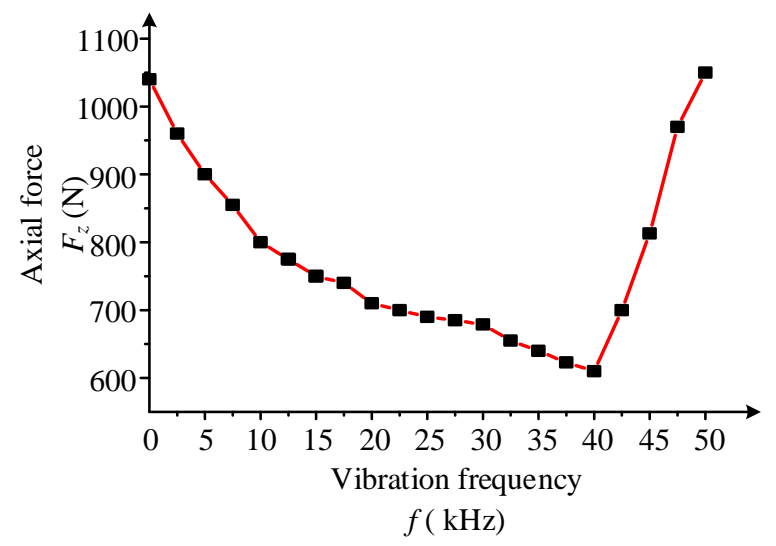

Fig.14 Curves of mean axial force of different vibration frequency change

Fig. 15 is a short time graph of the axial force when vibration frequency is $f=20 \mathrm{kHz}$. In this case, the tool was in contact with the sheet on average approximately $2 / 5$ of the time duration of one cycle, which can be calculated from ABAQUS simulation output data. With the increase in vibration frequency, rate of tool striking the plate material increases, and striking plate material with high frequency caused grains inside the sheet to vibrate, leading to increased activity within the metal. Thus, dynamic resistance of deformation for the sheet metal would be reduced. With increase in frequency, contact time of the tool and plate in each vibration cycle would be shortened. As a result, average forming force is smaller. Therefore, vibration frequency is inversely proportional to axial force.

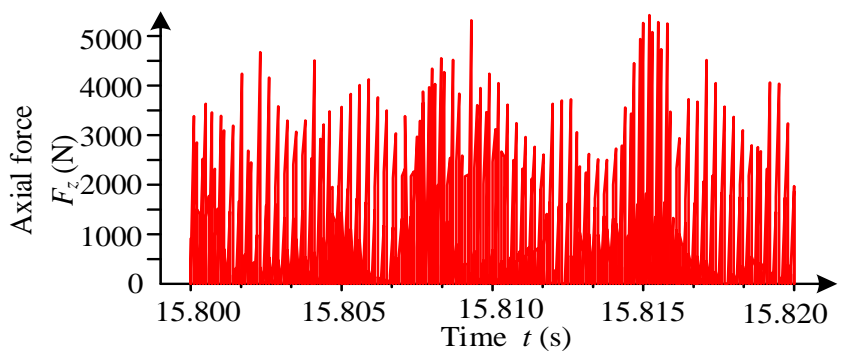

Fig. 15 Axial force for $f=20 \mathrm{kHz}$

Fig. 16 shows variation in axial force for $f=50 \mathrm{kHz}$. When $f=50 \mathrm{kHz}$ the mean axial force increased rapidly. This increase can be attributed to the principle of the US-SPIF. During US-SPIF, rebound is large. Rebound includes local and overall rebound in SPIF process. Local rebound occurs along with the forming process, which is one of the important reasons that caused the continuous fluctuations in the axial force. As seen from fig.12, the tool and plate material was always in contact because of no ultrasonic vibration. At this time, axial force is stable. It can be seen from fig. 15 that tool and plate were not always in contact at any time during ultrasonic vibration forming. However, When the frequency $f=50 \mathrm{kHz}$, high vibration frequency can result in increased local rebound of the plate. Which causes the tool and the plate to always be in contact with each other, leading to the axial force to be always greater than zero. It can be seen from fig. 16 that pulse axial force was reduced because of ultrasonic vibration. However, mean axial force was increased. Thus, high frequency vibration decreased the 
instantaneous axial force, but average axial force in a cycle was increased.

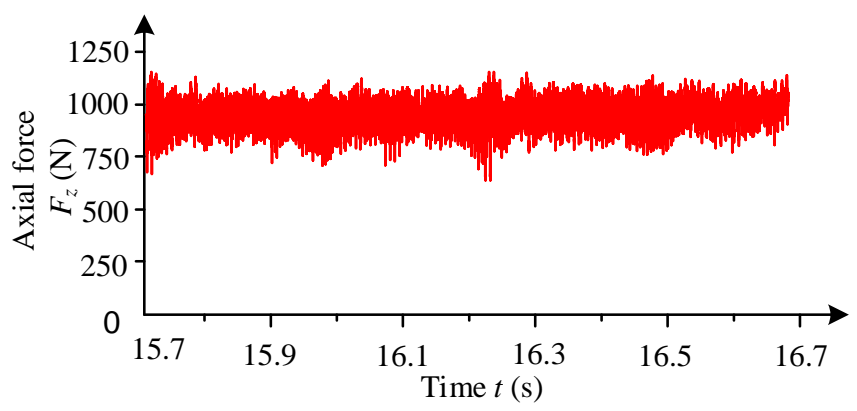

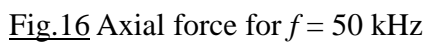

\subsubsection{Forming force under different amplitudes}

Fig. 17 shows simulation results for axial force at different amplitudes for vibration frequency $f=20 \mathrm{kHz}$. Each point in the figure represents average value of the axial force in the forming process of a cycle. As seen from fig.17, axial force at different amplitudes increased initially with depth increase in $z$ direction and gradually stabilized with further depth increase in $z$ direction. This trend was observed due to the small deformation and rebound of the sheet in the initial forming process. Over the course of the forming process, a gradual increase occurred for both deformation and rebound of the sheet metal. This resulted in a larger axial force. Finally, deformation and rebound stabilize and were at their maximum values. At this time, axial force also stabilized and was at its maximum. It can be seen from the figure that axial force with ultrasonic vibration was larger compared to the axial force without vibration, when amplitude is $A>40 \mu \mathrm{m}$.

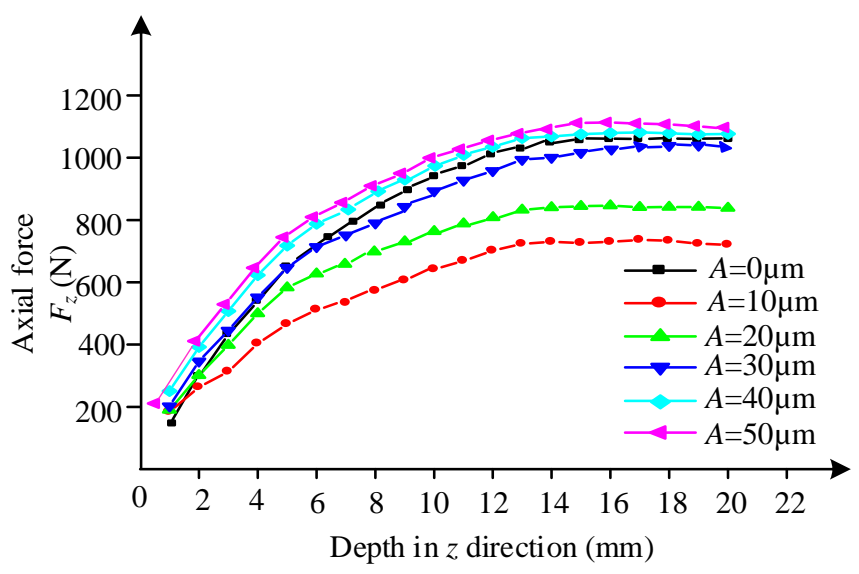

Fig. 17 Mean axial force along with depth in $\mathrm{z}$ direction

Fig.18 shows the relationship between amplitude and mean axial force in the process of US-SPIF. Magnitude of axial force under each amplitude is value of the axial force at steady state. It can be seen from the curve that increase in amplitude resulted in a gradual increase in the magnitude of the axial force when the amplitude larger than $10 \mu \mathrm{m}$. However, for amplitude less than $10 \mu \mathrm{m}$, increase in amplitude resulted in reduced mean axial force. 


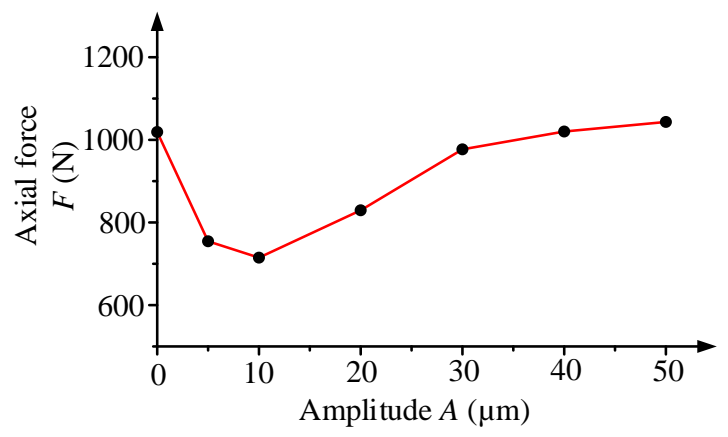

Fig.18 The mean axial force curve of different amplitudes

In US-SPIF, increase in amplitude results in a larger magnitude of the instantaneous press force of the tool in a vibration cycle. This results in a relatively larger deformation of the plate material per unit area. Also, tensile stress and deformation energy for the forming process were relatively large. This results in a large axial force. Thus, increase in amplitude cause an increase in the axial force. Effect on axial force with amplitude increase can be considered to be equivalent to the effect related to step-down. In addition, the ultrasonic vibration can reduce deformation resistance of the material, therefore, the increase in amplitude results in a reduced sheet fracture limit [20]. However, the axial force with frequency of $20 \mathrm{kHz}$, amplitude of $10 \mu \mathrm{m}$, is lower than the axial force without ultrasonic vibration. Therefore, there will be a decreasing trend between $A=0 \mu \mathrm{m}$ and $A=10 \mu \mathrm{m}$. It is important to select an appropriate amplitude for the process of sheet metal forming.

\section{Experimental validation}

\subsection{Experimental equipment}

As shown below are the facilities of experimental system used for US-SPIF:

(1) A NC machining center produced by Changzhen Machine Tool Group in China;

(2) Ultrasonic vibration system, which was composed of ultrasonic generator and ultrasonic vibration spindle device;

(3) A Kistler dynamometer and 9257B KISTLER three-way force transducers

(4) Signal acquisition system composed of a data collector, a charge amplifier and a PC host;

(5) Fixture of sheet metal, which was used to fix the sheet.

(6) Lycra material confocal microscopy produced by Germany Leica Microsystems was used to measure the sheet metal surface roughness.

The sensor used in this experiment was 9257B KISTLER three-way force transducer. The sensor was connected to a charge amplifier. Data was transmitted to a PC host which was used to record forming force. Forming force in $X, Y$ and $Z$ directions were recorded during the experiments.

First, forming forces at different amplitudes were experimentally determined. Next, validity of the simulation results was verified by comparing it against experiment results. Five experiments have been carried out with this system, and the experimental results were nearly consistent with each time, which can assure the repeatability of this experimental system runs.

\subsection{Experimental materials and parameter setting}

A Q235 sheet, $140 \mathrm{~mm} \times 140 \mathrm{~mm}$ square plate with an initial thickness of $1 \mathrm{~mm}$ was used in the experiments. Material of the tool was quenched bearing steel with a diameter of $10 \mathrm{~mm}$. Trajectory of the tool was set as a series of contour lines with the layer spacing set as $1 \mathrm{~mm}$ and forming angle was 45 degrees. Path of the tool was input into the $\mathrm{NC}$ vertical milling machine using $\mathrm{G}$ code, and tool was controlled to form the sheet metal. The 
experimental system used for ultrasonic single point incremental sheet metal forming is shown in fig. 19 .

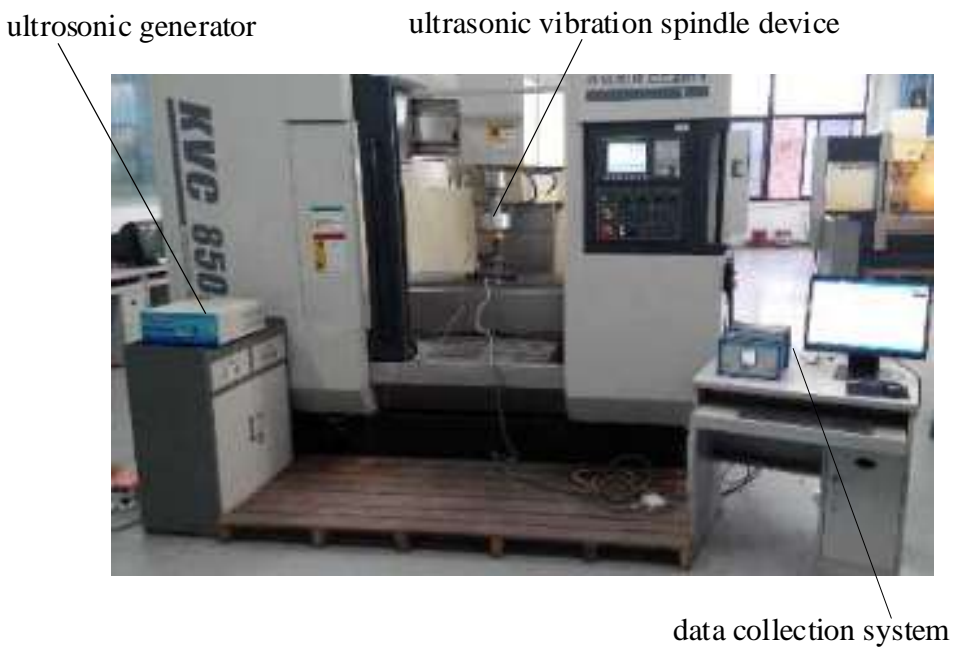

Fig.19 Experimental system used for US-SPIF

\subsection{Results}

Six different amplitudes were used in the experiment to form the sheet metal, and the other parameters (e.g. the diameter, revolving speed and feeding speed of the tool, the step-down, the thickness and material of the sheet metal and the frequency of the vibration) are controlled. In the experiments, the amplitudes of the tool are respectively set as $5 \mu \mathrm{m}, 10 \mu \mathrm{m}, 20 \mu \mathrm{m}, 30 \mu \mathrm{m}, 40 \mu \mathrm{m}, 50 \mu \mathrm{m}$ by adjust the power of ultrasonic generator. Fig. 20 shows the forming force measured during the experiments for an amplitude $A=10 \mu \mathrm{m}$ and vibration frequency $f$ $=20 \mathrm{kHz}$.

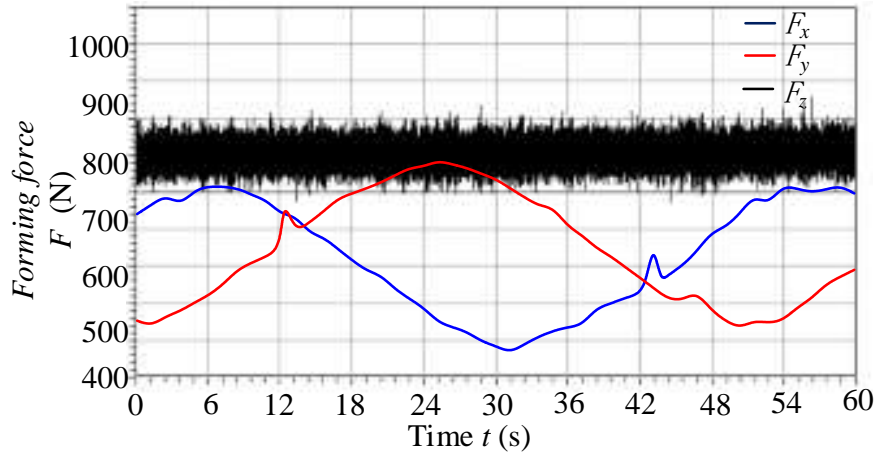

Fig.20 Forming force $F$ measured during the forming experiments

Fig. 21 is the contrast of average axial force between the simulations and the experiments. It can be seen from the figure that experimental value of the axial force increased with increase in amplitude. Also, trend in axial force as a function of amplitude was consistent for experimental and simulation results. There are some differences between the experimental values and the simulation values when the amplitudes are the same. Error between simulation and experiments was between $7.4 \%$ and $10.2 \%$ for amplitudes $0 \mu \mathrm{m}, 10 \mu \mathrm{m}, 20 \mu \mathrm{m}$ and $30 \mu \mathrm{m}$. This error is relatively smaller than the errors for amplitudes of $40 \mu \mathrm{m}$ and $50 \mu \mathrm{m}$, which ranges from $15.2 \%$ to $18.3 \%$. The transducer requires a greater energy input to generate a larger amplitude, which will result in heat generation of the transducer, and the resonant frequency of the spindle device will be less than $20 \mathrm{kHz}$ because of the heat. Therefore, there will be a larger forming force in the tests than ideal condition. Furthermore, the error between simulation and experiments will increase with the increasing amplitude. 


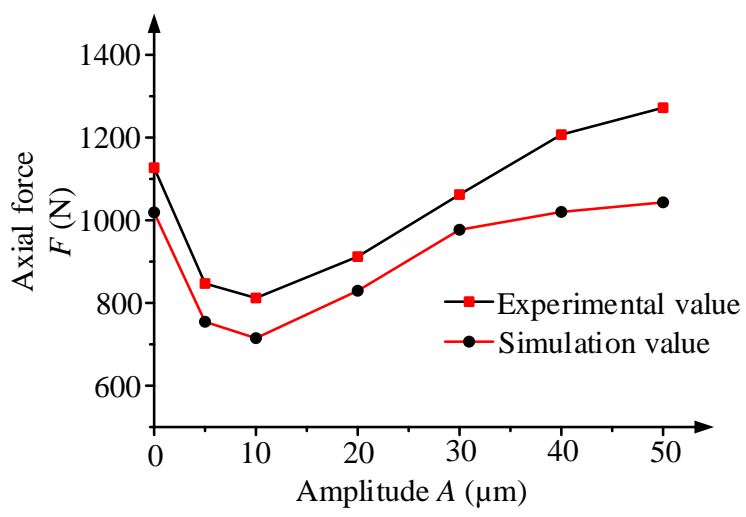

Fig.21 Comparison of simulation and experimental axial force as a function of amplitude

Fig.22 shows an image of two formed sheet metals, where one is an image of sheet metal formed using a typical method (i.e. without ultrasonic vibration) and the other using ultrasonic vibration with an amplitude of $20 \mu \mathrm{m}$ at $20 \mathrm{kHz}$. And the surface average roughness Ra of the former measured by the Lycra material confocal microscopy is about $6.3 \mu \mathrm{m}$, and the latter is about $3.2 \mu \mathrm{m}$. It can be concluded based on visual examination that application of ultrasonic vibration during forming improves surface quality of the sheet metal.
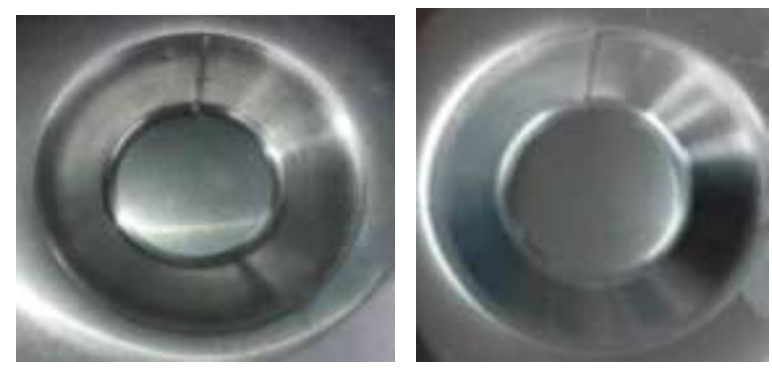

Fig.22 ordinary forming (left) and vibration forming (right)

As shown in Fig.23, use of a ball head results in the formation of a residual height in the sheet metal when the tool moves from position $O_{1}$ to $O_{2}$. Residual profile is represented by arc $\mathrm{AB}$ and arc AC. $A$ residual height $h$ always exists in the common incremental sheet metal forming. However, it can be reduced by changing forming parameters, such as increasing diameter of tool and reducing step-down. If the ultrasonic vibration is applied to an ordinary SPIF, residual height would be squeezed by the tool moving up and down. Effect of squeeze is more obvious with a larger amplitude. Thus, it can be inferred that increase in amplitude would increase surface quality of forming sheet metal under allowable amplitude conditions using US-SPIF.

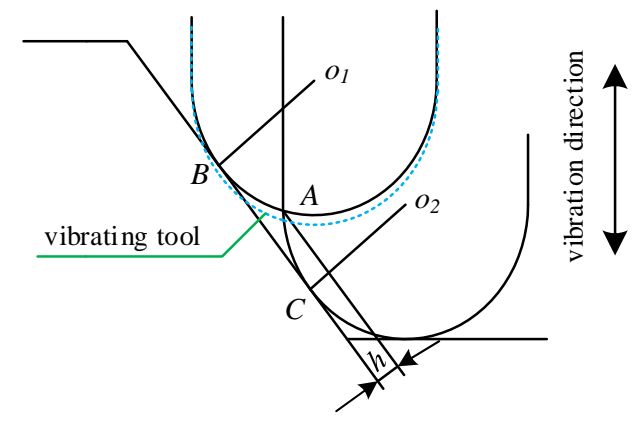

Fig.23 Sheet metal deformation map

\section{Conclusion}

In this paper, a new type of sheet metal forming technology using ultrasonic vibration was applied to SPIF. 
Forming force during the forming process can cause fracture and affect accuracy of the sheet metal. Design of US-SPIF equipment can be based on this study, which takes into account magnitude and changing law of forming force. In this paper, ABAQUS finite element software was used to simulate and analyze influence of different frequencies and amplitudes of ultrasonic vibration on the forming force of SPIF.

The trend in axial force using ultrasonic vibration forming was found to be consistent with forming without ultrasonic vibration. Results show that there is an initial and gradual increase followed by a stabilization at a steady state value. In US-SPIF, vibration frequency was found to have a significant influence on axial force. Increase in vibration frequency caused a decrease in the mean axial force. However, the mean axial force increased dramatically when frequency was larger than $40 \mathrm{kHz}$. For a frequency of $50 \mathrm{kHz}$, magnitude of mean axial force was larger than axial force without ultrasonic vibration. When frequency was less than $50 \mathrm{kHz}$, increase in frequency resulted in reduced contact time contact between the tool and sheet. For frequency larger than $50 \mathrm{kHz}$, tool and sheet material were always in contact due to increased rebound. Also, mean axial force for this case increased significantly, and was greater than axial force without vibration. Influence of amplitude on the mean axial force was increased with increase in amplitude of the mean axial force when the amplitude larger than $10 \mu \mathrm{m}$. However, for amplitude less than $10 \mu \mathrm{m}$, increase in amplitude resulted in reduced mean axial force. When, amplitude was greater than $40 \mu \mathrm{m}$, the mean axial force for ultrasonic vibration was larger than that without vibration. In forming process, increase in amplitude resulted in improved surface quality of the formed sheet. Also, residual height would be squeezed out by high frequency vibration of the tool. Thus, with appropriate conditions, a larger amplitude would result in better surface quality.

\section{Acknowledgements}

The authors would like to thank support from the National Science Foundation of China (51675422, 51375381). Shaanxi Provincial Department Education Key Laboratory Foundation of China (15JS067), and China State Key Laboratory of Mechanical Transmission Open Foundation (SKLMT-KFKT-201415).

\section{Reference}

[1] J. Cao, Z.C. Xia, T.G. Gutowski, et al., A hybrid forming system: electrical-assisted double side incremental forming (EADSIF) process for enhanced formability and geometrical flexibility, Northwestern University, 2012.

[2] 松原茂夫. タイレスフオーミングとしての数值制御逐次成形法. プレス技术, 36 (1998) 109-115. (In Japanese)

[3] M. Durante, A. Formisano, A. Langella, et al., The influence of tool rotation on an incremental forming process, Journal of Materials Processing Technology. 209 (2009) 4621-4626.

[4] C. Henrard, C. Bouffioux, P. Eyckens, et al., Forming forces in single point incremental forming: prediction by finite element simulations, validation and sensitivity, Computati-onal Mechanics. 47 (2010) 573-590.

[5] R. Aerens, P. Eyckens, A. Van Bael, et al., Force prediction for single point incremental forming deduced from experimental and FEM observations, The International Journal of Advanced Manufacturing Technology. 46(2009) 969-982.

[6] I. Bagudanch, G. Centeno, C. Vallellano, et al., Forming force in single point incremental forming under different bending conditions, Procedia Engineering. (2013) 354-360.

[7] J. Belchior, M. Guillo, E. Courteille, et al., Off-line compensation of the tool path deviations on robotic machining: Application to incremental sheet forming, Robotics and Computer Integrated Manufacturing. 29 (2013) 58-69. 
[8] F. Blaha, B. Langenecker, Elongation of zinc monocrystals under untrasonic action, Die Nater Wissen-schaften. 42 (1955) 556.

[9] J. Petruzelka, J. Sarmanova, A. Sarman, The effect of ultrasound on tube drawing, Joural of Materials Processing Technology, 60 (1996) 661-668.

[10] R.E. Green, Non-linear effects of high-power ultrasonics in crystalline solids, Ultrasonics. 13 (1975) 117-127.

[11] Z. Huang, M. Lucas, M.J. Adams, Influence of ultrasonics on upsetting of a model paste, Ultrasonics. 40 (2002) 43-48.

[12] Y.M. Huang, Y.S. Wu, J.Y. Huang, The influence of ultrasonic vibration-assisted micro-deep drawing process, International Journal of Advanced Manufacturing Technology. 71 (2014) 5-8.

[13] M.A. Rasoli, A. Abdullah, M. Farzin, et al., Influence of ultrasonic vibrations on tube spinning process, Journal of Materials Processing Technology. 212 (2012) 1443-1452.

[14] M. Inoue, Studies on ultrasonic metal tube drawing, Memoira of Sagami Institute of Technology. 19 (1984) $1-7$.

[15] M. Vahdati, R. Mahdavinejad, S. Amini, Investigation of the ultrasonic vibration effect in incremental sheet metal forming(ISMF) Process, Proceedings of the Institution of Mechanical Engineers Part B Journal of Engineering Manufacture. (2015) 1-12.

[16] G. Ambrogio, L. Filice, F. Guerriero, et al., Prediction of incremental sheet forming process performance by using a neural network approach, Int J Adv Manuf Technol. 54 (2011) 921-930.

[17] N. Alberti, L. Fratini, Innovative sheet metal forming processes: numerical simulations and experimental tests, Journal of Materials Processing Technology. 150 (2004) 2-9.

[18] J. Duflou, Y. Tunckol, A. Szekeres, et al., Experimental study on force measurements for single point incremental forming. Journal of Materials Processing Technology. 189 (2007) 65-72.

[19] L. Filice, G. Ambrogio, F. Micari, et al., On-Line control of single point incremental forming operations through punch force monitoring. CIRP Annals - Manufacturing Technology. 55(1) (2006) 245-248.

[20] T. Wen, C.L. Pei, C.K. Li, Application of vibration in plastic forming processes, Casting Forging Welding. 38 (2009) 114-117. (In Chinese) 